\title{
The Substance Abuse and Mental Health Services Administration Buprenorphine Practitioner Locator Misrepresents Access to Buprenorphine
}

\author{
Precious Anyanwu, PharmD1, Tyler J. Varisco, PhD, PharmD¹, Matthew A. Wanat, PharmD, BCPS, BCCCP, FCCM 2,3, Shweta \\ Bapat, $\mathrm{PhD}^{1}$, Kasey Claborn, $\mathrm{PhD}^{4}$, J. Douglas Thornton, PharmD, PhD, BCPS ${ }^{1,3}$
}

1) Department of Pharmaceutical Health Outcomes and Policy, University of Houston College of Pharmacy, TX, USA

2) Department of Pharmacy Practice and Translational Research, University of Houston College of Pharmacy, TX, USA

3) Prescription Drug Misuse Education and Research Center, University of Houston College of Pharmacy, TX, USA

4) Department of Psychiatry, The University of Texas Dell Medical School, TX, USA

\section{Corresponding author:}

Tyler J. Varisco, PhD, PharmD

Prescription Drug Misuse Education and Research Center

University of Houston College of Pharmacy

4849 Calhoun Rd

Houston, TX 77204

Email: tjvarisc@central.uh.edu

\section{Abstract:}

Aims: To compare county-level differences in the number of buprenorphine prescribers listed in the publicly available Substance Abuse and Mental Health Services Administration (SAMHSA) Buprenorphine Practitioner Locator and in the Drug Enforcement Administration's (DEA) Controlled Substance Act (CSA) database and to determine if disparities in access exist in poorer areas with more non-white residents.

Design: Cross-sectional study

Setting: Texas

Measurements: County-level counts of buprenorphine prescribers were calculated from both the publicly available SAMHSA buprenorphine practitioner locator list and the DEA CSA database. These were then used to estimate the number of providers per 100,000 residents in each county. Regional variation in access to buprenorphine was compared descriptively across the state using poverty data from the US Census and countylevel demography from the Texas Demographic Center.

Results: This study found $68.8 \%$ more $X$-waivered providers on the DEA CSA database $(n=2,622)$ with at least one provider reported in 125 of 144 counties in the state (49.2\%) compared to the SAMHSA Buprenorphine Practitioner Locator $(n=1,553)$ with at least one provider reported in 103 counties $(40.5 \%)$. This difference was magnified in Texas Public Health Region 11. This is the poorest region of the state $(23.7 \%$ of residents below the federal poverty line) and contains the most non-white residents $87.4 \%$ vs $54.9 \%$ (SD: $13.6 \%$ ). This region had the lowest number of buprenorphine prescribers with 3.8 providers per 100,000 on the DEA CSA database and 2.5 providers per 100,000 in the SAMHSA Buprenorphine Practitioner Locator.

Conclusions: The lack of a complete, public registry of buprenorphine prescribers makes it difficult for patients to identify a convenient buprenorphine prescriber and for referring physicians to help their patients access care. This may be especially true in poorer and more diverse areas with fewer buprenorphine prescribers.

Keywords: Buprenorphine, Opioid substitution treatment; Opioid-related disorders; health services accessibility; Spatial Analysis; Demography 


\section{INTRODUCTION}

It is estimated that $90 \%$ of individuals with opioid use disorder (OUD) are in need of treatment, yet remain untreated. ${ }^{1}$ Buprenorphine, a schedule III controlled substance, is approved by the Food and Drug Administration (FDA) for the treatment of OUD. ${ }^{2}$ Unlike methadone and extended release naltrexone, buprenorphine can be prescribed by a Drug Addiction Treatment Act of 2000 (DATA 2000) waivered provider, a and dispensed by a community pharmacy. The DATA 2000 was intended to attenuate unmet treatment need by improving access to care, however, progress has been limited. Bridging this gap will require that several, known barriers to buprenorphine treatment be addressed. These include patient access to providers, restrictions on who can prescribe buprenorphine, and limits on the number of patients prescribers can concurrently treat with medications for opioid use disorder (MOUD). ${ }^{3}$

Until April 2021, to prescribe buprenorphine, prescribers who were not board certified addiction specialists were required to complete additional training prior to registering with the Substance Abuse and Mental Health Services Administration (SAMHSA) as DATA Waivered providers. ${ }^{4}$ In April 2021, policy from the United States Department of Health and Human Services allowed any prescriber with a valid Drug Enforcement Administration registration to prescribe buprenorphine after submitting notice of their intent to prescribe to SAMHSA. These prescribers may then treat up to 30-patients with buprenorphine. 5 Though this new policy may prove beneficial, access to buprenorphine has historically been limited. ${ }^{6-9} \mathrm{~A}$ recent study measured geographic proximity to buprenorphine treatment providers using the Substance Abuse and Mental Health Services Administration (SAMHSA) Buprenorphine Practitioner Locator. This study found that there are 14.3 providers for every 100,000 persons with OUD in the US. Texas held the lowest ratio with an average of 5.46 providers per

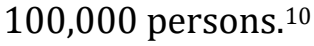

That study, however, joined a host of others that used the SAMHSA Buprenorphine Practitioner Locator to quantify access to buprenorphine. ${ }^{10-14}$ All of these may be limited as the list only contains contact information from providers who willingly provide their practice information to SAMHSA. In addition the list has been criticized as being only marginally useful to patients as it contains misleading and out of date information. ${ }^{12}$ Like any other form of self-reported data collection, the SAMHSA list may, therefore, under-report the number of DATA waivered providers in any community.

Fortunately, a more reliable data source does exist. In the United States, all entities that manufacture, sell, prescribe, or dispense controlled substances must be registered with the DEA in accordance with Title 21 of the US Code, the Controlled Substances Act.15 The DEA maintains a database of all entities registered under the act and indicates all prescribers registered under DATA 2000 within this database. The DEA CSA database is, therefore, a complete record of all DATA 2000 waivered prescribers in the United States. Unlike the SAMHSA Buprenorphine Practitioner Locator that is free for public search, the DEA CSA database is a subscription-based service and is not readily accessible by the public or for referring primary care practitioners. This means that those who need it most lack access to the only comprehensive registry of DATA waivered prescribers. This could be particularly problematic in Texas, a state with a minority majority population, vast rural expanses, and low access to healthcare, known barriers to buprenorphine access. ${ }^{16}$ Measuring access to buprenorphine along socioeconomic gradients is critical to the development of interventions intended to improve resource allocation in OUD treatment and a state as diverse as Texas provides an ideal laboratory.

Multiple attempts have been made to quantify access to buprenorphine using provider registries, however, none have evaluated the potential measurement error associated with using the error-prone, self-reported information contained in the SAMHSA Practitioner Locator. ${ }^{10-14,17,18}$ This is especially problematic amidst efforts to expand access to treatment. Developing policy and public health interventions with imperfect information may lead to hasty decisions and poor resource allocation. It is therefore critical to determine how many providers exist and to begin to identify populations who would benefit from targeted efforts to improve access. The objective of this study is to compare county-level differences in the number of buprenorphine prescribers listed in the publicly available SAMHSA Practitioner Locator and in the Drug Enforcement Administration's (DEA) Controlled Substance Act (CSA) database and to determine if disparities in access exist in poorer areas with more non-white residents. 


\section{METHODS \\ Design data sources}

This was a cross-sectional study performed in September of 2020 intended to compare two, distinct registries of DATA 2000 waivered providers: the DEA CSA Database and the SAMHSA Buprenorphine Practitioner Locator. To obtain provider information from the DEA CSA database, a subscription was purchased from the National Technical Information Service (NTIS) in September 2020.19 Providers registered to prescribe buprenorphine are flagged with "Data Waved" or "DW" in the description of their record. The DEA CSA database also disclosed the providers' DEA registration number as well as the provider name, practitioner type (physician or advance practice provider), DATA 2000 waiver expiration date, active status, postal code, and the maximum number of patients the provider is authorized to treat with buprenorphine at any given time. The SAMHSA Buprenorphine Practitioner Locator List was downloaded, in the same month, from the public link provided by SAMHSA. ${ }^{20}$ The SAMHSA Buprenorphine Practitioner Locator provided the providers' name, physical address, postal code, telephone number, and fax number.

The Quarter 3 of 2020, Department of Housing and Urban Development (HUD) United States Postal Services Zip Code to County Crosswalk File was used to aggregate providers at the county level. While zip codes may be spatially associated with a county, some span county boundaries. In their crosswalk file, HUD provides a variable summarizing the proportion of addresses in a zip code that lie within each county. We therefore assigned each zip code to the county where most of its residential and commercial addresses were located. County population estimates were gathered from the US Census Annual Estimates of Resident Population. Poverty data was gathered from the US Census Small area income and poverty estimates (SAIPE) program. ${ }^{21}$ County level demography was identified from the Texas Demographic Center. ${ }^{22}$

\section{Measures and analysis}

At the state level, the number of individual prescribers was calculated within each list. This was repeated at the county-level. To provide a visualization of the geospatial distribution of treatment providers in Texas, these counts were used to construct choropleth maps demonstrating the number of DATA waivered prescribers in each county from each list. In all choropleth maps within, darker areas represent counties with higher level of access while hashed, blue shaded areas represent counties with lower levels of access. The number of providers at the county level from each list was then divided by the 2019 US Census Resident Population Estimate and then multiplied by 100,000 to provide an estimate of the number of DATA waivered prescribers per 100,000 population at the county level. The SAMHSA Buprenorphine Practitioner Locator is intended to improve access to treatment across the population. To coordinate public health efforts across Texas, the Department of State Health Services has divided the state's eleven administrative regions into eight, distinct public health regions each with its' own unique demographic and socioeconomic characteristics. To begin to characterize equity of access to buprenorphine across the state, we estimated the number of providers per 100,000 residents in each of these regions from both the SAMHSA and DEA lists. We then characterized the proportion of residents below the federal poverty limit and proportion of non-white residents in each region. ${ }^{21,22}$

\section{RESULTS}

\section{Count of X-waivered providers in Texas}

The DEA CSA database reported 2,622 X-waivered providers in the state of Texas whereas the SAMHSA Buprenorphine Practitioner Locator reported 1,553 X- waivered providers. There were 68.8\% more X-waivered providers found on the DEA CSA database compared to the SAMHSA Buprenorphine Practitioner Locator. Most Xwaivered providers were physicians $(\mathrm{N}=2,038,77.7 \%)$ and $584(22.3 \%)$ were advanced practice providers. The remaining $0.83 \%(n=24)$ were military practitioners. Table 1 list the provider type and patient capacity limits of DATA waivered prescribers in Texas according to the DEA CSA database.

\section{County level differences}

There are a total of 254 counties in the state of Texas. The SAMHSA Buprenorphine Practitioner Locator reported 103 counties (40.5\%) with at least one X-waivered provider, while the DEA CSA database reported 125 counties (49.2\%) with at least one provider. Figure 1 is a choropleth map that illustrates the count of X- waivered providers per county from the two references. There are 22 counties in Texas where the SAMHSA Buprenorphine Practitioner Locator reported zero X-waivered providers, but the DEA CSA database reported at least one X- 
waivered provider. These 22 counties have a total population of 564,465 residents according to the 2019 United States Census Bureau (Figure 2)

There were 104 counties (40.9\%) with discrepancies in the total number of providers between lists. Of these 104 counties, the DEA CSA database reported more providers in 93 of the counties, with 11 counties having a higher number of providers in the SAMHSA Buprenorphine Practitioner Locator (Figure 3). A summary of providers found in the two references as well as the number of providers per 100,000 persons per county is listed in Table 2. The DEA CSA Database reported a higher mean number of providers per 100,000 county residents with 10.7 (SD: 10.4) vs 7.5 (SD: 6.7) listed on the SAMHSA list (Figure 4).

\section{Regional differences between lists}

In all regions, more providers were listed on the DEA list than the SAMHSA list. The difference between lists was highest in the central part of the state, region 7, with 12.0 providers per 100,000 residents listed on the DEA list and 5.8 providers per 100,000 on the SAMHSA list, a $105.3 \%$ difference. The lowest number of buprenorphine prescribers per 100,000 residents was observed in region 11, the southern-most region in the state along the Texas-Mexico border. Here, there were 3.8 providers per 100,000 on the DEA list and 2.5 providers per 100,000 on the SAMHSA list compared to a mean of 8.8 (SD: 2.1) and 5.0 (SD: 1.1) within each of the other regions, respectively. Of note, region 11 is also the poorest region of the state with $23.7 \%$ of residents below the federal poverty line compared to $14.1 \%$ (SD: $2.2 \%$ ) across the other regions. There were more non-white residents in this region than any other region of the state, $87.4 \%$ vs $54.9 \%$ (SD: $13.6 \%$ ) statewide with $85.4 \%$ of the region's residents identifying as Latinx. ${ }^{22}$ For reference, a map of all public health regions in the state is provided in Appendix 1 and Table 3 provides a summary of the number of providers on each list, their prevalence per 100,000 residents, and rates of poverty and non-white residency within each region.

\section{DISCUSSION}

The SAMHSA Buprenorphine Practitioner Locator was intended to help patients identify practitioners who prescribe buprenorphine for the treatment of OUD. This provider list has been utilized by researchers to measure treatment access to X-waivered providers, to quantify the number of X-waivered providers nationally, and to estimate the association between X-waivered provider availability and opioid related morbidity and mortality.9,10,12,13,23-25 The results presented here indicate that the SAMHSA Buprenorphine Practitioner Locator under reported X-waivered providers in Texas by nearly $40 \%$. Without accurate data on practitioner availability, much of this research is undoubtedly biased. What is known is that even of those prescribers who list their information on the SAMHSA registry, just over one in four (27.7\%) were actively enrolling new patients. ${ }^{12}$ Given the gap in registered and publicly listed prescribers described here, the number of DATA waivered providers actually treating patients may be significantly lower than initially expected. Limited initial appointment availability from providers, in combination with the overall decreased number of providers listed on the SAMHSA Buprenorphine Practitioner Locator suggests that our baseline understanding of the current access landscape is significantly skewed.

Epidemiological estimates of the number of buprenorphine prescribers in an area taken from the SAMHSA Buprenorphine Practitioner Locator are not only inaccurate, but they are also unreliable. In one recent study using the SAMHSA list, Texas was estimated to have $5.46 \mathrm{X}$-waivered providers per 100,000 persons. ${ }^{10}$ In this analysis of the SAMHSA practitioner locator, conducted months later, we found Texas to have 7.5 prescribers per 100,000 residents, a difference of 37.8\%. Both estimates are much lower than the known 10.7 (SD:10.4) per 100,000 persons per county in Texas as calculated from the DEA list. Listings on the SAMHSA locator are voluntarily provided by the prescriber and are, thus, labile to non-response bias where the most motivated prescribers may be more likely to register their practice compared to those not currently enrolling new patients or those not motivated to prescribe buprenorphine. The number of providers on the SAMHSA list may change over time as providers can remove their information from the list electively. This makes it difficult to truly define access in any given geographic area.

Published access estimates from the SAMHSA list may be used by policy makers to design interventions to improve access to buprenorphine. Based on these findings, there are current initiatives to eliminate caps on the number of patients a provider may treat or to allow any provider to prescribe buprenorphine.$^{26,27}$ While these 
could potentially be reasonable policy solutions, all policy changes impose some level of opportunity cost and take resources from areas of equal or greater need. To ensure that resources are directed to where they are needed most, accurate estimates of treatment capacity are needed.

In addition to their implications to research and policy, the consequences of imperfect information become more tangible when considered from the perspective of patient care. Patients and prescribers alike ostensibly rely on the SAMHSA Buprenorphine Practitioner Locator when identifying a treatment provider. Without seeing all available prescribers, patients may be led to believe that their nearest prescriber is further than expected. This may dissuade them from entering treatment or lead them to choose an inconvenient prescriber and struggle to remain in treatment. 28,29

Finally, this study broadly described buprenorphine access in socioeconomic and racial/ethnic terms. The results suggest that areas with a higher proportion of non-white residents and impoverished areas may have less access to buprenorphine prescribers. This was especially true in the southernmost public health region in Texas where most residents are Latinx and more than one-in-five fall below the federal poverty line. While these results do not provide an adequate description of unmet treatment need in impoverished or minority majority areas, they do lay the groundwork for more intensive work to identify and address the needs of socioeconomically and racially/ethnically diverse communities.

Patterns of opioid use among the Texas Latinx community have varied dramatically over the course of the $21^{\text {st }}$ century, however, the lack of treatment capacity in South Texas observed here suggests that there is still a need for the expansion of access to culturally competent treatment for opioid use disorder in this area. ${ }^{30} \mathrm{An}$ important first step to addressing the treatment needs of the Latinx community in Texas would be to understand opioid related harm in South Texas and other predominantly Latinx areas. This is difficult to do as only seven of the 19 counties in public health region 11 report opioid overdose mortality to the Texas Department of State Health Services. ${ }^{31}$ Without better data on opioid related morbidity and mortality, we cannot determine if the disparity in access to treatment in this impoverished and highly diverse area is linked to disproportionally higher incidence of opioid related harm.

There are some limitations to this study, first not all DATA waivered prescribers may actively treat patients with opioid use disorder. As mentioned earlier in the text, the DEA registry may over-estimate treatment capacity. The SAMHSA Buprenorphine Practitioner Locator also changes regularly. The capacity estimates provided in this study may have changed since data collection in September 2020. Finally, this was a descriptive study. All results should be viewed as exploratory, and any inference made from these results should be performed with caution. Still, to our knowledge, this was the first study to attempt to compare treatment capacity between these two different and independently useful data sources. This study demonstrates the need to carefully evaluate buprenorphine treatment capacity and to identify and characterize areas with low access to buprenorphine. ${ }^{32}$

\section{CONCLUSION}

Clinicians, researchers, and policymakers alike should be aware that the SAMHSA Buprenorphine Practitioner Locator consists of self-reported information and may be incomplete. Previous studies performed with data from the list may have greatly underestimated patients' access to treatment in the state of Texas. More work is needed to begin to quantify the gap between treatment capacity and treatment need. Starting with better data is imperative to understanding how patients access care and where care is needed most. Policymakers and health services researchers should carefully consider how this may influence resource allocation in opioid use disorder treatment. Decisions made with partial knowledge can hardly be considered evidence based. Until treatment capacity can be accurately measured, interventions to improve treatment capacity will continue to falter. 


\section{REFERENCES}

1. National Survey on Drug Use and Health. 2020. https://www.datafiles.samhsa.gov/study-series/nationalsurvey-drug-use-and-health-nsduh-nid13517. Accessed September 9,2020.

2. Nielsen S, Larance B, Lintzeris N. Opioid Agonist Treatment for Patients With Dependence on Prescription Opioids. JAMA. 2017;317(9):967-968.

3. Haffajee RL, Bohnert ASB, Lagisetty PA. Policy Pathways to Address Provider Workforce Barriers to Buprenorphine Treatment. Am J Prev Med. 2018;54(6 Suppl 3):S230-S242.

4. Walsh SL, Eissenberg T. The clinical pharmacology of buprenorphine: extrapolating from the laboratory to the clinic. Drug Alcohol Depend. 2003;70(2 Suppl):S13-27.

5. US Department of Health and Human Services. 86 FR 22439: Practice Guidelines for the Administration of Buprenorphine for Treating Opioid Use Disorder. Washington, District of Columbia; 2021.

6. A. Dabrowska VRG, L.N. Sacco, B.T. Yeh. The SUPPORT for Patients and Communities Act (P.L. 115-271): Food and Drug Administration and Controlled Substance Provisions (No. R45405). In: Service CR, ed. Washington, D.C2018.

7. Dick AW, Pacula RL, Gordon AJ, et al. Growth In Buprenorphine Waivers For Physicians Increased Potential Access To Opioid Agonist Treatment, 2002-11. Health Aff (Millwood). 2015;34(6):1028-1034.

8. Ghertner R. U.S. trends in the supply of providers with a waiver to prescribe buprenorphine for opioid use disorder in 2016 and 2018. Drug Alcohol Depend. 2019;204:107527.

9. Rosenblatt RA, Andrilla CH, Catlin M, Larson EH. Geographic and specialty distribution of US physicians trained to treat opioid use disorder. Ann Fam Med. 2015;13(1):23-26.

10. Langabeer JR, Stotts AL, Cortez A, Tortolero G, Champagne-Langabeer T. Geographic proximity to buprenorphine treatment providers in the U.S. Drug Alcohol Depend. 2020;213:108131.

11. Drake C, Donohue JM, Nagy D, Mair C, Kraemer KL, Wallace DJ. Geographic access to buprenorphine prescribers for patients who use public transit. J Subst Abuse Treat. 2020;117:108093.

12. Flavin L, Malowney M, Patel NA, et al. Availability of Buprenorphine Treatment in the 10 States With the Highest Drug Overdose Death Rates in the United States. J Psychiatr Pract. 2020;26(1):17-22.

13. Jones CW, Christman Z, Smith CM, et al. Comparison between buprenorphine provider availability and opioid deaths among US counties. J Subst Abuse Treat. 2018;93:19-25.

14. Spetz J, Toretsky C, Chapman S, Phoenix B, Tierney M. Nurse Practitioner and Physician Assistant Waivers to Prescribe Buprenorphine and State Scope of Practice Restrictions. JAMA. 2019;321(14):1407-1408.

15. Administration DE. Title 21 United States Code (USC) Controlled Substances Act. In:2010.

16. Hansen H, Siegel C, Wanderling J, DiRocco D. Buprenorphine and methadone treatment for opioid dependence by income, ethnicity and race of neighborhoods in New York City. Drug Alcohol Depend. 2016;164:14-21.

17. Knudsen HK, Lin LA, Lofwall MR. Adoption of the 275-patient buprenorphine treatment waiver for treating opioid use disorder: A state-level longitudinal analysis. Subst Abus. 2020;41(2):259-268.

18. Knudsen HK, Studts JL. Physicians as Mediators of Health Policy: Acceptance of Medicaid in the Context of Buprenorphine Treatment. J Behav Health Serv Res. 2019;46(1):151-163.

19. DEA REGISTRATION RECORD LAYOUT. 2019. https://dea.ntis.gov/recordlayout.pdf.

20. Administration SAaMHS. Buprenorphine Practitioner Locator. 2021; https://www.samhsa.gov/medication-assisted-treatment/practitioner-program-data/treatmentpractitioner-locator. Accessed September 21,2020, 2020.

21. Bureau UC. Small area income and poverty estimates (SAIPE) program. Census Bureau QuickFacts. 2019.

22. Texas Population Estimates Program. Texas Demographic Center. Age, Sex, and Race/Ethnicity for State and Counties. 2019.

23. Beetham T, Saloner B, Wakeman SE, Gaye M, Barnett ML. Access to Office-Based Buprenorphine Treatment in Areas With High Rates of Opioid-Related Mortality: An Audit Study. Ann Intern Med. 2019;171(1):1-9.

24. Ghertner R, Ali MM. Increases in Providers With Buprenorphine Waivers in the United States From 2016 to 2019. Psychiatr Serv. 2020;71(9):971. 
25. Quest TL, Merrill JO, Roll J, Saxon AJ, Rosenblatt RA. Buprenorphine therapy for opioid addiction in rural Washington: the experience of the early adopters. J Opioid Manag. 2012;8(1):29-38.

26. Stein BD, Gordon AJ, Dick AW, et al. Supply of buprenorphine waivered physicians: the influence of state policies. J Subst Abuse Treat. 2015;48(1):104-111.

27. Huskamp HA, Busch AB, Souza J, et al. How Is Telemedicine Being Used In Opioid And Other Substance Use Disorder Treatment? Health affairs (Project Hope). 2018;37(12):1940-1947.

28. Bunting AM, Oser CB, Staton M, Eddens KS, Knudsen H. Clinician identified barriers to treatment for individuals in Appalachia with opioid use disorder following release from prison: a social ecological approach. Addict Sci Clin Pract. 2018:23.

29. Saunders JB, Jarlenski MP, Levy R, Kozhimannil KB. Federal and State Policy Efforts to Address Maternal Opioid Misuse: Gaps and Challenges. Womens Health Issues. 2018;28(2):130-136.

30. Washburn M, Torres LR, Moore NE, Mancillas A. The intersection of the "opioid crisis" with changes in US immigration policy: Contextual barriers to substance abuse research with Latinx communities. Journal of Social Work Practice in the Addictions. 2020;20(4):335-340.

31. Texas Vital Statistics. Texas Department of State Health Services. Drug overdose deaths in Texas. 2017.

32. ASHP guidelines for institutional use of controlled substances. American journal of hospital pharmacy. 1974;31(6):582-588. 
Table 1: Provider type and capacity limits of DATA waivered prescribers in Texas according to the DEA ${ }^{1}$ Controlled

Substances Act database

\section{Provider Type}

Number of Providers

Practitioner

Authorized to treat 30

1,465

Authorized to treat 100

Authorized to treat 275

Military Practitioner

Authorized to treat 30

Authorized to treat 100

Authorized to treat 275

Military Nurse Practitioner Authorized to treat 30

Authorized to treat 100 Authorized to treat 275

Military Physician Assistant

Authorized to treat 30

Authorized to treat 100

Authorized to treat 275

Nurse Practitioner

Authorized to treat 30

Authorized to treat 100

Authorized to treat 275

Physician Assistant

Authorized to treat 30

66

Authorized to treat 100

Authorized to treat 275

1Drug Enforcement Administration 
Table 2: Differences in the number and distribution of DATA waivered providers in Texas as reflected by the SAMHSA ${ }^{1}$ practitioner locator and DEA ${ }^{2}$ Controlled Substance Act database.

\begin{tabular}{lrr}
\hline \hline & \multicolumn{1}{c}{ SAMHSA } & \multicolumn{1}{c}{ DEA } \\
\cline { 2 - 3 } Total Number of Providers & 1,553 & 2,622 \\
Counties with at least 1 Provider & $103 / 254(40.6 \%)$ & $125 / 254(49.2 \%)$ \\
Counties with 0 providers & $151 / 254(59.4 \%)$ & $129 / 254(50.8 \%)$ \\
Mean Providers Per 100,000 per county & 7.49 (SD:6.66) & $10.73($ SD:10.43) \\
Median Providers Per 100,000 per county & 5.42 (IQR:4.74) & 7.59 (IQR:6.63) \\
\hline \hline
\end{tabular}

${ }^{1}$ Substance Abuse and Mental Health Services Administration

${ }^{2}$ Drug Enforcement Administration 


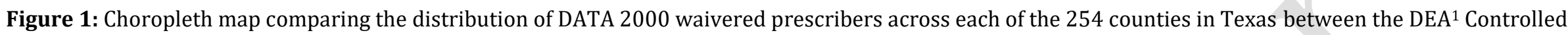

DATA 2000 Waivered Prescribers: DEA

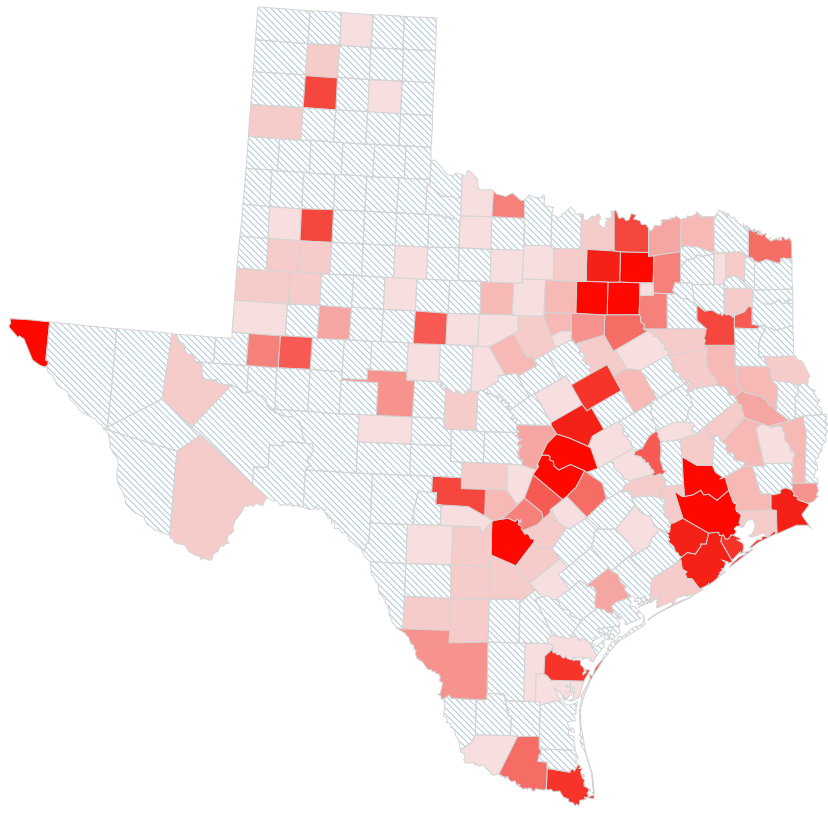

Count of providers, DEA registry 0
6 TO 7
15 TO 20 1
8 TO 9
21 TO 23 2 TO 3
10 TO 1 24 TO 35

4 TO 5 More than 50 36 TO 49
DATA 2000 Waivered Prescribers: SAMHSA

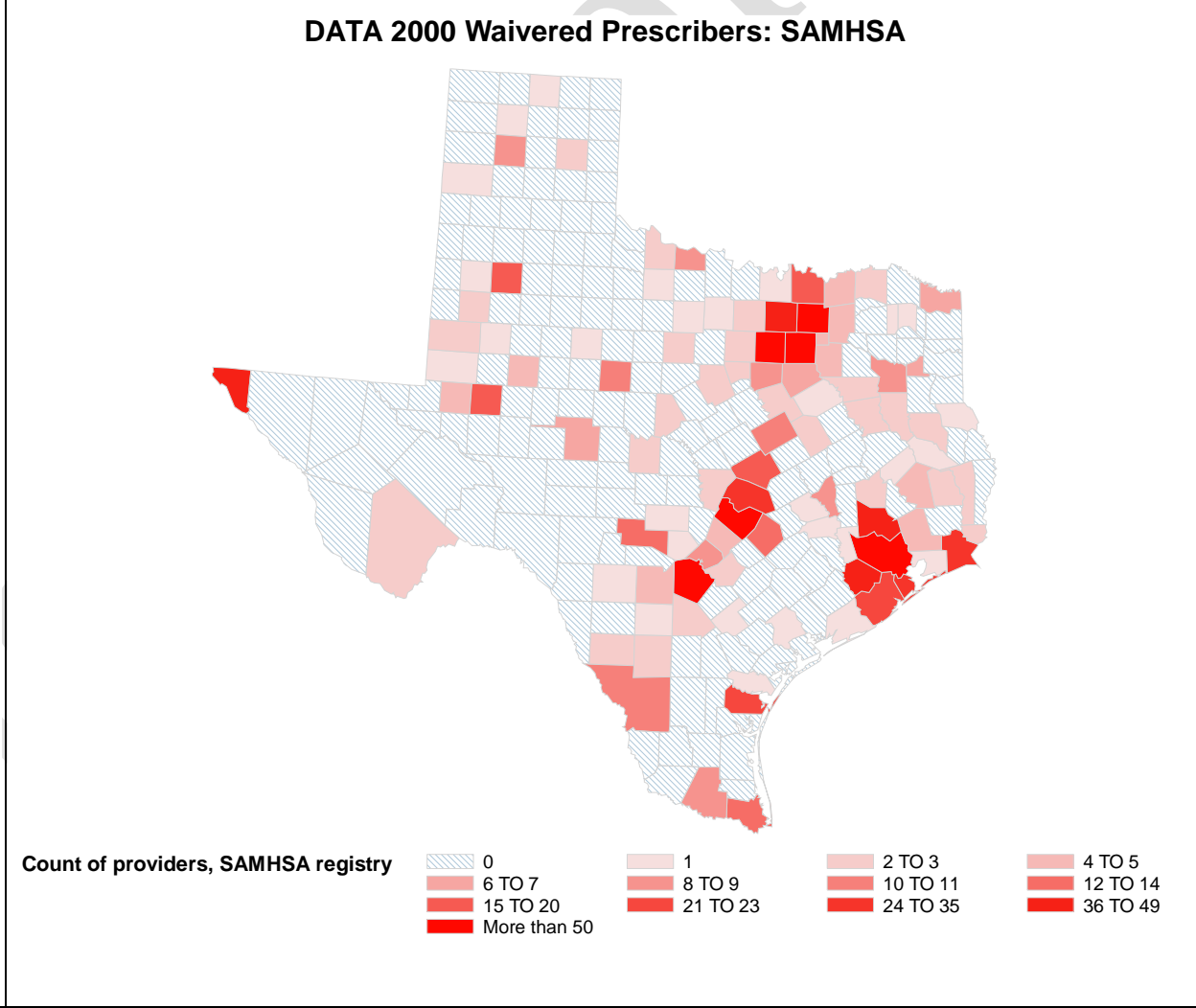

Substances Act Database and the SAMHSA² Practitioner Locator

1Drug Enforcement Administration

2Substance Abuse and Mental Health Services Administration 
Figure 2: Map depicting the 22 counties (cumulative population: of 564,465) in Texas with at least one DATA waivered prescriber listed in the Drug Enforcement Administration Controlled

Substances Act database and no prescribers listed in the Substance Abuse and Mental Health Services Administration Practitioner Locator. 
Figure 3: Difference in number of DATA waivered prescribers in each county in Texas between the SAMHSA ${ }^{1}$ Practitioner Locator and DEA ${ }^{2}$ Controlled Substance Act database. Red areas display counties with more prescribers listed on the DEA list than the public SAMHSA locator. Blue counties are those with more providers on the SAMHSA list than the DEA list.

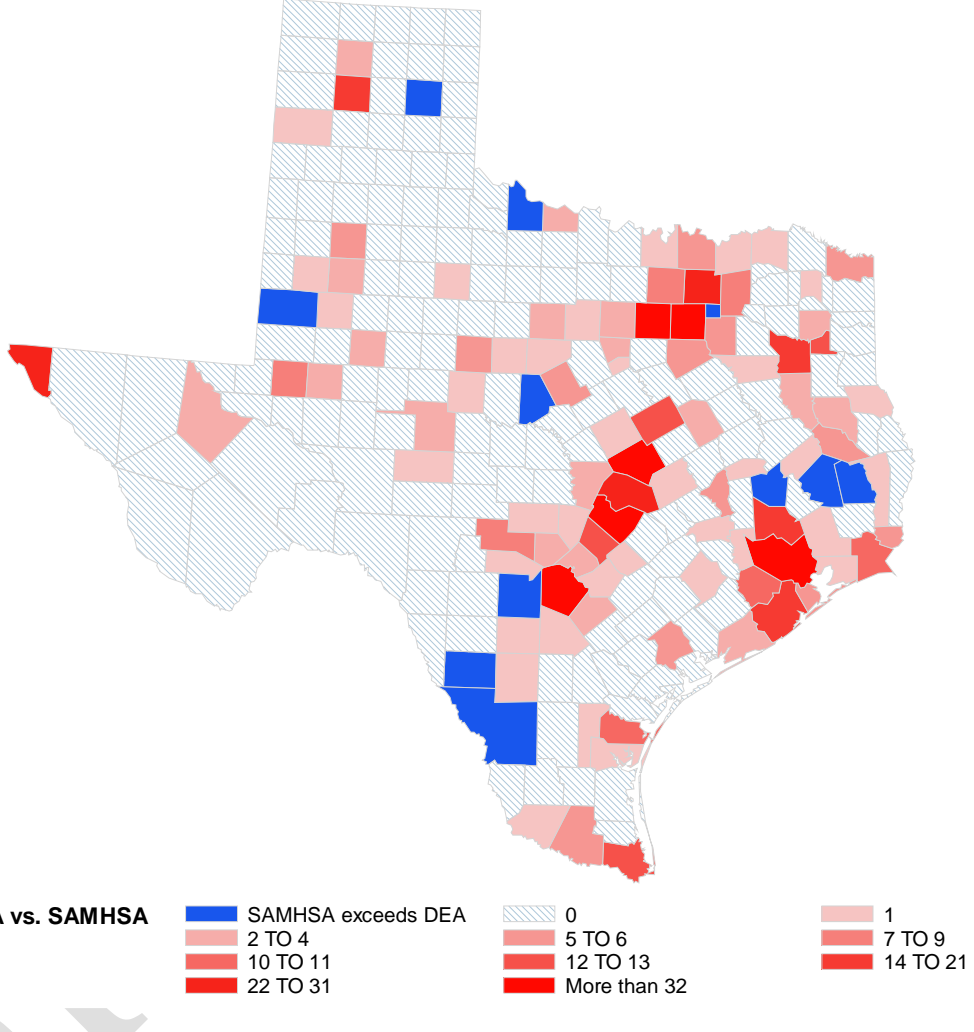

Difference: DEA vs. SAMHSA

7 TO 9
14 TO 21

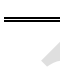

1Substance Abuse and Mental Health Services Administration

2Drug Enforcement Administration 


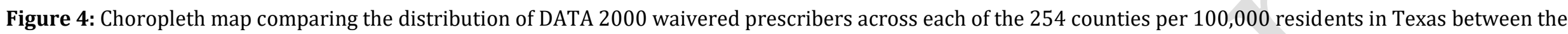

Choropleth map of DATA waivered providers registered with DEA

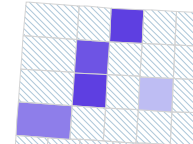

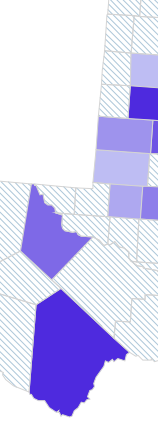

X-Waivered Prescribers/100,000: DEA
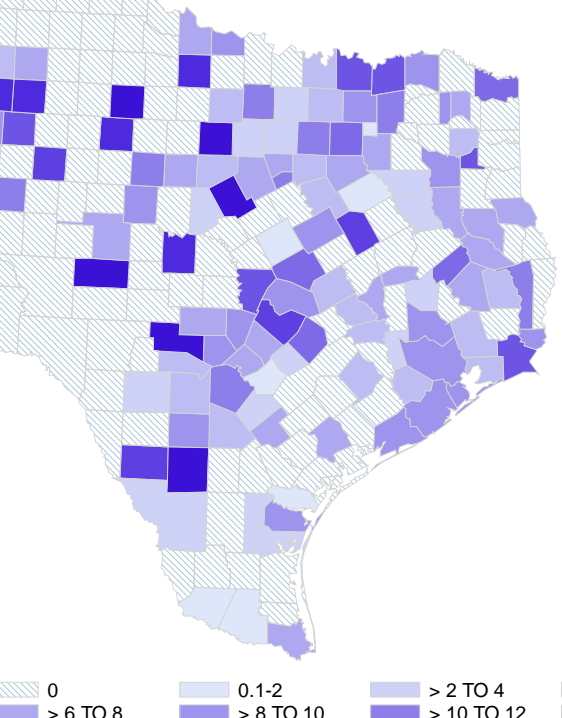

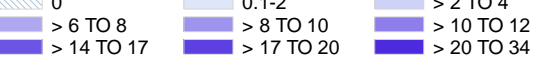

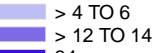

$>4$ TO 6
$>12$ TO 14

Choropleth map of DATA waivered providers registered with SAMHSA

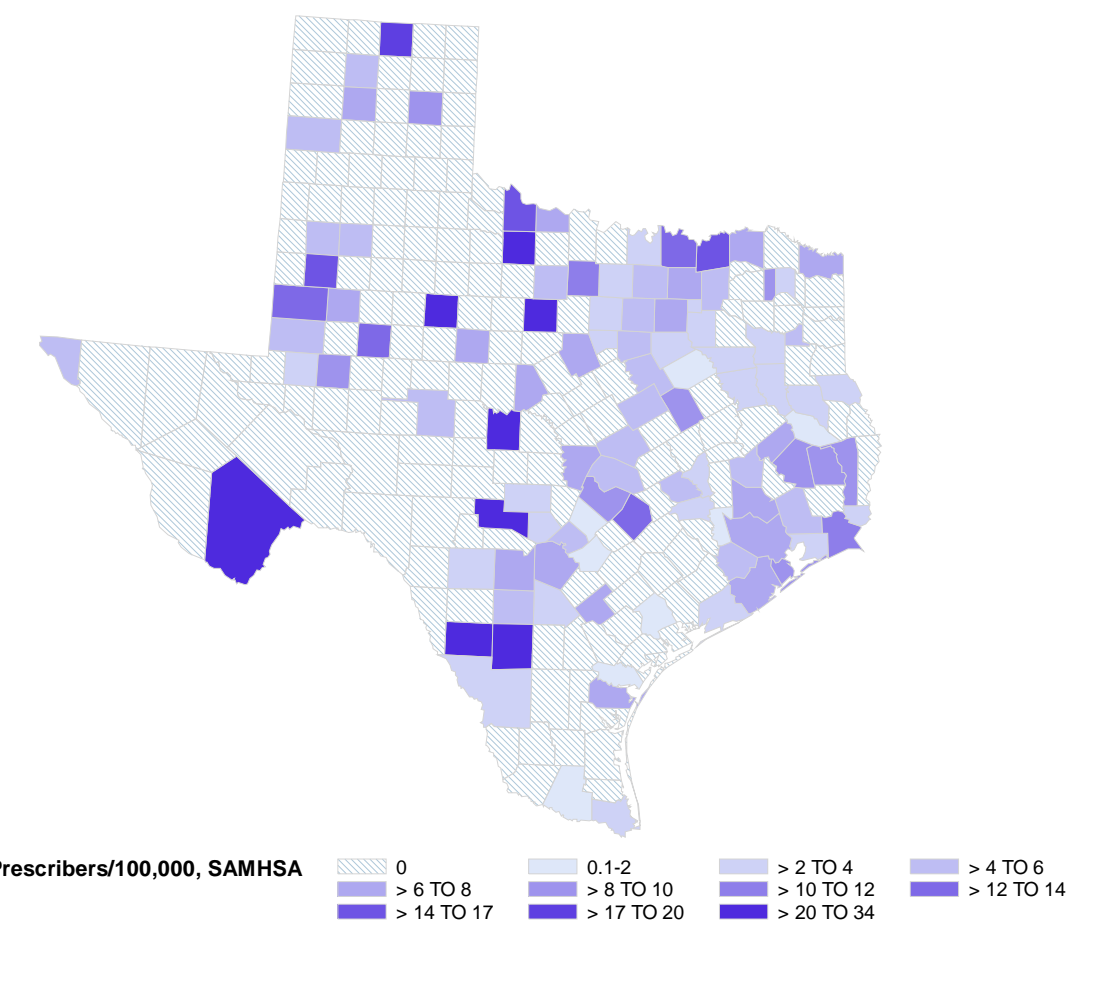

DEA ${ }^{1}$ Controlled Substances Act Registry and the SAMHSA ${ }^{2}$ Practitioner Locator

${ }^{1}$ Drug Enforcement Administration

${ }^{2}$ Substance Abuse and Mental Health Services Administration 
Table 3: Demographic and socioeconomic characteristics of the eight public health regions in Texas and the distribution of DATA waivered prescribers in each region according to the DEA ${ }^{1}$ Controlled Substances Act database and the SAMHSA ${ }^{2}$ practitioner Locator.

\section{Public Health Region}

Region 1 (North Texas)

Region 2/3 (North central Texas)

Region 4/5N (East Texas)

Region 6/5S (Southeast Texas)

Region 7 (Central Texas)

Region 8 (Southwest Texas)

Region 9/10 (West Texas)

Region 11 (South Texas)

\begin{tabular}{|c|c|c|c|c|c|}
\hline \multicolumn{2}{|c|}{$\begin{array}{l}\text { Number of } \\
\text { Providers }\end{array}$} & \multicolumn{2}{|c|}{$\begin{array}{c}\text { Providers per } 100,000 \\
\text { Population }\end{array}$} & \multirow{2}{*}{$\begin{array}{c}\text { Population Below } \\
\text { the Federal } \\
\text { Poverty Limit } \\
(\%)\end{array}$} & \multirow{2}{*}{$\begin{array}{c}\text { Non-white } \\
\text { Population (\%) }\end{array}$} \\
\hline SAMHSA & DEA & SAMHSA & DEA & & \\
\hline 33 & 59 & 3.8 & 6.8 & $15.9 \%$ & $48.5 \%$ \\
\hline 501 & 853 & 5.9 & 10.0 & $10.8 \%$ & $51.6 \%$ \\
\hline 49 & 95 & 3.2 & 6.2 & $16.5 \%$ & $34.0 \%$ \\
\hline 454 & 669 & 5.9 & 8.8 & $13.2 \%$ & $62.8 \%$ \\
\hline 210 & 431 & 5.8 & 12.0 & $11.9 \%$ & $46.9 \%$ \\
\hline 172 & 304 & 5.7 & 10.0 & $14.5 \%$ & $66.0 \%$ \\
\hline 77 & 116 & 5.0 & 7.6 & $16.1 \%$ & $74.4 \%$ \\
\hline 57 & 87 & 2.5 & 3.8 & $23.7 \%$ & $87.4 \%$ \\
\hline
\end{tabular}

1Drug Enforcement Administration

${ }^{2}$ Substance Abuse and Mental Health Services Administration 